\title{
Synthesis of Wideband Damping Filter for Electric Traction Systems
}

\author{
Igor F. Nikolaeva, Ivan A. Stashkova, \\ Artiom F. Sinjagovsky ${ }^{b}$ and Valery P. Dovgun*b \\ ${ }^{a}$ Service of Electrification and Power Supply \\ of Krasnoyarsk Directorate of Infrastructure, \\ Branch of JSC «Russian Railways» \\ 156 Mira, Krasnoyarsk, 660021, Russia \\ ${ }^{b}$ Siberian Federal University \\ 79 Svobodny, Krasnoyarsk, 660041, Russia
}

Received 11.06.2015, received in revised form 12.08.2015, accepted 27.12.2015

In this paper design procedure of wideband damping power filters for electric traction systems is considered. Compensating systems designed with the proposed approach provides for correction frequency characteristics of traction system at the expense of impedance matching between filter and contact feeder in the prescribed frequency range.

Keywords: power quality, harmonics, wideband power harmonic filter.

Citation: Nikolaev I.F., Stashkov I.A., Sinjagovsky A.F., Dovgun V.P. Synthesis of wideband damping filter for electric traction systems, J. Sib. Fed. Univ. Eng. technol., 2016, 9(1), 61-70. DOI: 10.17516/1999-494X-2016-9-1-61-70.

(C) Siberian Federal University. All rights reserved

* Corresponding author E-mail address: Vdovgun@sfu-kras.ru 


\title{
Синтез широкополосных \\ демпфирующих фильтров \\ для систем тягового электроснабжения
}

\author{
И.Ф. Николаев ${ }^{\text {a }}$, И.А. Сташков ${ }^{a}$, \\ А.Ф. Синяговскийб \\ ${ }^{a}$ Служба электрификации и электроснабжения \\ Красноярской дирекции инфраструктуры, \\ филиала ОАО «Российские железные дороги» \\ Россия, 660021, Красноярск, пр. Мира, 156 \\ ${ }^{6}$ Сибирский федеральный университет \\ Россия, 660041, Красноярск, пр. Свободньій, 79
}

В статье рассмотрена прочедура расчета широкополосньх демпфирующих фильтров для систем тягового электроснабжения, основанная на использовании методов синтеза резистивно нагруженных LC-четырехполюсников. Предлагаемый подход позволяет получить фильтрокомпенсирующие устройства, обеспечивающие коррекцию частотных характеристик системы тягового электроснабжения за счет согласования сопротивления фильтра и тяговой сети в заданном диапазоне частот.

Ключевые слова: качество электроэнергии, высшие гармоники, широкополосные силовые фильтры гармоник.

\section{Введение}

На электрифицированных железных дорогах используются системы тягового электроснабжения (СТЭ) однофазного переменного тока напряжением 25 кВ. В качестве силовых установок на электровозах используют выпрямительно-инверторные преобразователи. Особенность таких преобразователей - низкий коэффициент мощности, а также значительные искажения формы токов и напряжений в контактной сети. В спектрах токов преобладают 3-, 5- и 7-я гармонические составляющие.

Искажения тока вызывают значительные искажения кривой напряжения. По отношению к гармоникам высокого порядка протяженная контактная сеть ведет себя как линия с распределенными параметрами. Волновые процессы в тяговой сети сопровождаются резонансными явлениями, которые еще более увеличивают искажение напряжения.

Анализ качества электроэнергии в системах тягового электроснабжения, проведенный в [1-3], показал, что основными факторами, влияющими на характеристики СТЭ, выступают пониженное напряжение в конце протяженного участка, режимные перенапряжения, вызванные резонансными явлениями в контактной сети, а также уменьшение средней величины напряжения.

Режимы работы сетей тягового электроснабжения значительно отличаются от режимов промышленных или муниципальных систем электроснабжения, поэтому при разработке мероприятий по улучшению качества электроэнергии необходимо учитывать перечисленные особенности СТЭ. Для тяговых сетей переменного тока необходимы многофункциональные

$$
-62-
$$


устройства, обеспечивающие компенсацию реактивной мощности, подавление мощных низкочастотных гармоник и коррекцию частотных характеристик СТЭ. Устанавливаемые ФКУ должны обеспечивать электромагнитную совместимость тяговой сети с цепями питания устройств автоматики и телемеханики.

Подавление низкочастотных гармоник $(n=3,5)$ целесообразно осуществлять с помощью узкополосных резонансных фильтров [4] либо активных фильтров [5]. Для коррекции частотных характеристик тяговой сети необходимы широкополосные демпфирующие фильтры, обеспечивающие согласование сопротивления ФКУ с волновым сопротивлением тяговой сети в диапазоне высокочастотных гармоник. Для снижения потерь сопротивление демпфирующего фильтра должно иметь максимальное значение на частоте основной гармоники. На частотах выше 300 Гц входное сопротивление фильтра должно быть равно волновому сопротивлению тяговой сети.

Демпфирующие фильтры для систем тягового электроснабжения рассмотрены в работах [4-6]. Схемы демпфирующих звеньев второго и третьего порядка показаны на рис. 1.

Следует отметить, что в [4-6] отсутствуют регулярные процедуры расчета демпфирующих ФКУ. Значения элементов определяются, по существу, методом проб и ошибок. Такой подход позволяет проектировать только простейшие фильтры второго порядка.

Демпфирующие фильтры, изображенные на рис. 1, представляют резистивно нагруженные $L C$-четырехполюсники, реализующие передаточную функцию фильтра верхних частот. Для проектирования таких структур целесообразно использовать методы синтеза пассивных фильтров, хорошо разработанные в классической теории цепей.

В настоящей статье рассмотрен общий метод расчета широкополосных демпфирующих фильтров, основанный на представлении фильтра в виде резистивно нагруженного $L C$ четырехполюсника. Предлагаемый метод позволяет обобщить известные структуры демпфирующих фильтров, используемых в системах тягового электроснабжения, а также получить новые конфигурации таких устройств. Он может быть использован для расчета фильтров произвольного порядка.

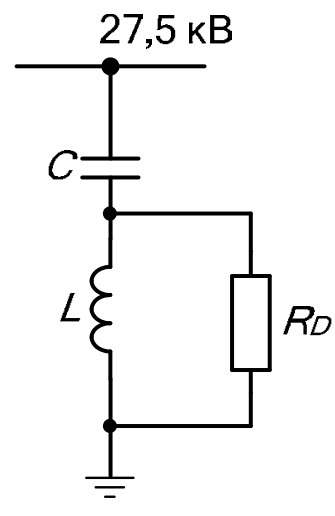

a

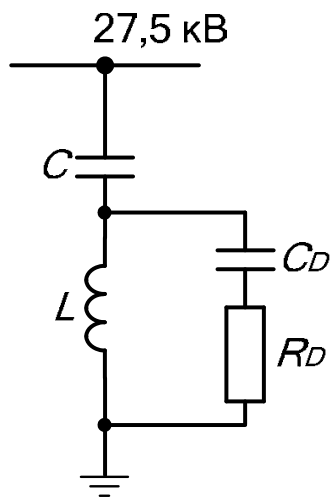

6

Рис. 1. Демпфирующие звенья второго и третьего порядка 


\section{Синтез демпфирующих фильтров}

Предлагаемая процедура проектирования демпфирующего фильтра включает три этапа.

1. На первом этапе выполняется расчет нормированного фильтра - прототипа нижних частот (ФНЧ), имеющего частоту среза, равную 1 рад/с, и нагруженного на сопротивление 1 Ом (рис. 2). Обозначим индуктивности и емкости элементов фильтра-прототипа $L_{i}^{(1)}, C_{i}^{(1)}$.

2. На втором этапе НЧ-прототип трансформируется в фильтр верхних частот (ФВЧ) с помощью преобразования НЧ-ВЧ:

$$
s=\frac{\omega_{\mathrm{c}}}{p}
$$

Здесь $\omega_{c}$ - частота среза фильтра верхних частот. Такое преобразование трансформирует передаточную функцию ФНЧ-прототипа в передаточную функцию ФВЧ с частотой среза $\omega_{c}$. При этом конденсаторы заменяются катушками, индуктивность которых равна $L^{(2)}=1 / C^{(1)} \omega_{\text {c }}$, Гн. Катушки НЧ-прототипа заменяются конденсаторами емкостью $C^{(2)}=1 / L^{(1)} \omega_{c}, \Phi$.

3. На третьем этапе производится денормирование сопротивлений ветвей фильтра верхних частот, для того чтобы обеспечить согласование входного сопротивления фильтра с волновым сопротивлением тяговой сети. Сопротивление нагрузочного резистора в денормированном фильтре равно волновому сопротивлению сети: $R=Z_{\mathrm{B}}$. Индуктивности и емкости вычисляются по формулам: $L^{(3)}=Z_{\text {в }} L^{(2)}, C^{(3)}=C^{(2)} / Z_{\text {в }}$.

Наиболее трудоемкий первый этап, связанный с расчетом НЧ-прототипа фильтра, поэтому рассмотрим его подробнее. Представим синтезируемую цепь в виде $L C$-четырехполюсника, нагруженного на сопротивление $R=1$ Ом (рис. 2).

Передаточная функция фильтра, выраженная через $y$-параметры четырехполюсника, имеет вид

$$
H(s)=\frac{U_{2}}{U_{1}}=\frac{y_{21}(s)}{y_{22}(s)+1} .
$$

Задача реализации передаточной функции $H(s)$, определяемой формулой (2), сводится к одновременной реализации параметров $y_{21}(s)$ и $y_{22}(s) L C$-четырехполюсника. Если нули передачи $H(s)$ расположены в бесконечности, фильтр-прототип может быть реализован с помощью

Рис. 2. $L C$-четырехполюсник

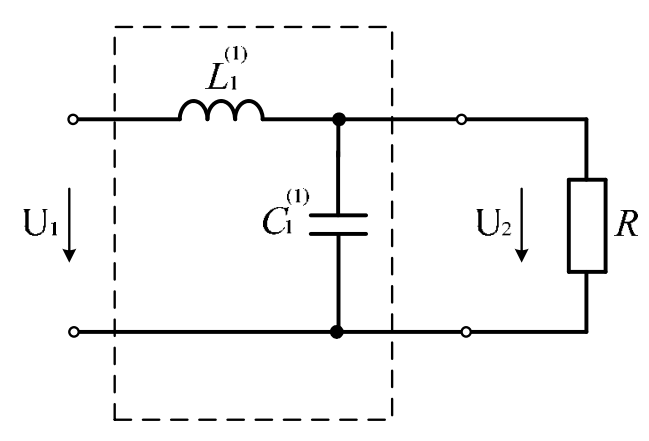


разложения параметра $y_{22}(s)$ в цепную дробь. В этом случае синтезируемая структура представляет лестничную $L C$-цепь.

В некоторых случаях для уменьшения потерь используют демпфирующие фильтры, имеющие нули передачи на частоте основной гармоники $[4,6]$. Для реализации передаточных функций с конечными нулями необходимы более сложные процедуры, например метод смещения нуля $[7,8]$. Однако подробный анализ методов реализации реактивных четырехполюсников выходит за рамки данной статьи. Различные варианты процедуры синтеза реактивных четырехполюсников, реализующих широкополосные фильтры, рассмотрены в [9].

Первый этап процедуры синтеза можно значительно упростить, если использовать в качестве НЧ-прототипа фильтры Баттерворта или Чебышева. Информацию о них можно найти в справочниках и руководствах по расчету аналоговых фильтров [8, 10]. В табл. 1 и 2 приведены значения элементов нормированных НЧ-прототипов второго-четвертого порядка.

Графики частотных характеристик входной проводимости демпфирующих фильтров, реализующих передаточные функции Баттерворта второго и третьего порядка, показаны на рис. 3. Частота среза демпфирующего фильтра выбрана равной 300 Гц, сопротивление нагрузочного резистора 100 Ом. Предлагаемые фильтры имеют монотонные частотные характеристики входного сопротивления и могут обеспечить согласование характеристик в широком диапазоне частот.

\section{Фильтрокомпенсирующие устройства для систем тягового электроснабжения}

В качестве иллюстрации предложенного метода рассмотрим пример многофункционального ФКУ для системы тягового электроснабжения. Устройство должно обеспечивать компенсацию реактивной мощности, шунтирование наиболее мощных третьей и пятой гармоник тока, а также коррекцию частотной характеристики тяговой сети на частотах, превышающих 300 Гц.

Таблица 1. Значения элементов фильтра нижних частот Баттерворта

\begin{tabular}{|c|c|c|c|c|}
\hline$n$ & $C_{1}, \Phi$ & $L_{2}, \Gamma \mathrm{H}$ & $C_{3}, \Phi$ & $L_{4}, \Gamma_{\mathrm{H}}$ \\
\hline 2 & 0.707 & 1.414 & - & - \\
\hline 3 & 0.5 & 1.333 & 1.5 & - \\
\hline 4 & 0.3827 & 1.0824 & 1.5772 & 1.5307 \\
\hline
\end{tabular}

Таблица 2. Значения элементов фильтра нижних частот Чебышева

\begin{tabular}{|c|c|c|c|c|}
\hline$n$ & $C_{1}, \Phi$ & $L_{2}, \Gamma \mathrm{H}$ & $C_{3}, \Phi$ & $L_{4}, \Gamma_{\mathrm{H}}$ \\
\hline 2 & 0.911 & 0.9957 & - & - \\
\hline 3 & 1.0118 & 1.3332 & 1.5088 & - \\
\hline 4 & 1.0495 & 1.4126 & 1.9093 & 1.2817 \\
\hline
\end{tabular}




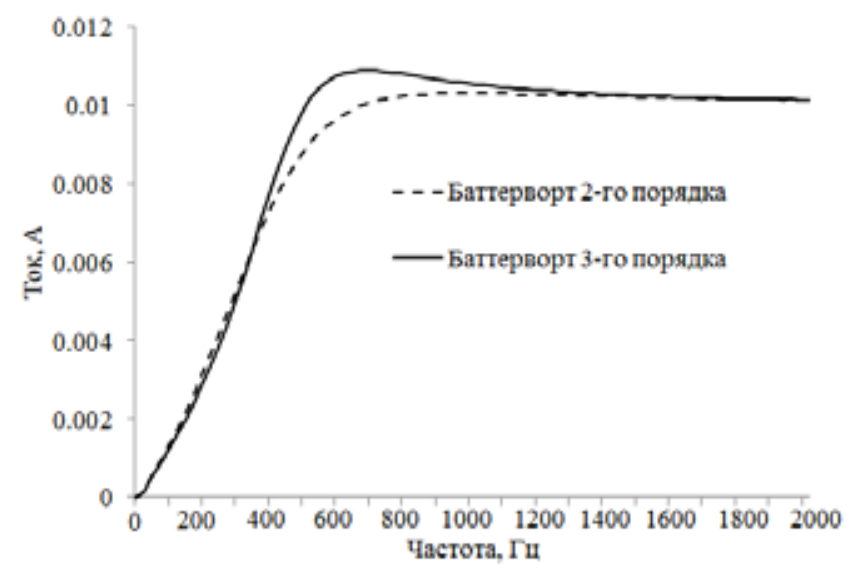

Рис. 3. Частотная характеристика входной проводимости фильтров Баттерворта второго и третьего порядка

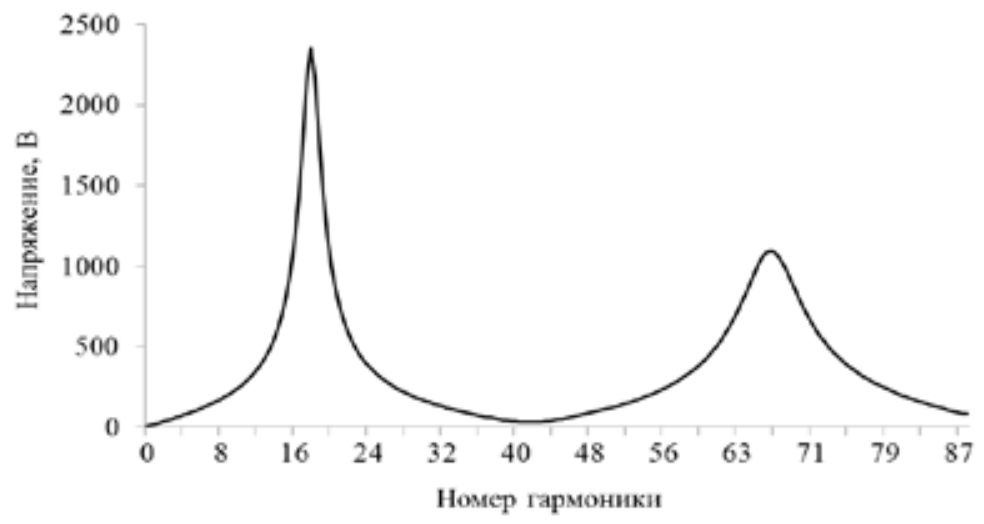

Рис. 4. Частотная характеристика входного сопротивления тяговой сети

Частотная характеристика входного сопротивления тяговой сети показана на рис. 4. Характеристика имеет резонансные максимумы, расположение и амплитуда которых зависят от длины участка и параметров трансформатора. На рис. 5 представлена кривая напряжения на токоприемнике ЭПС. Суммарный коэффициент гармоник напряжения составляет 32 \%.

Схема многофункционального ФКУ показана на рис. 6. Узкополосные звенья $L_{1}-C_{1}$ и $L_{2}-C_{2}$ осуществляют ослабление третьей и пятой гармоник. Широкополосное демпфирующее звено третьего порядка, рассчитанное с помощью предложенного метода, реализует максимально плоскую характеристику на частотах выше 300 Гц. Мощность ФКУ равна 3400 квар. Значения элементов ФКУ представлены в табл. 3.

Частотная характеристика системы тягового электроснабжения с ФКУ, установленным в конце участка, показана на рис. 7 (кривая 1). Максимумы в низкочастотной области соответствуют резонансам в параллельных колебательных контурах, образованных узкополосными звеньями и индуктивностью тяговой сети. Отметим, что на частотах высших гармоник величина сопротивления уменьшилась более чем в 10 раз.

$$
-66-
$$




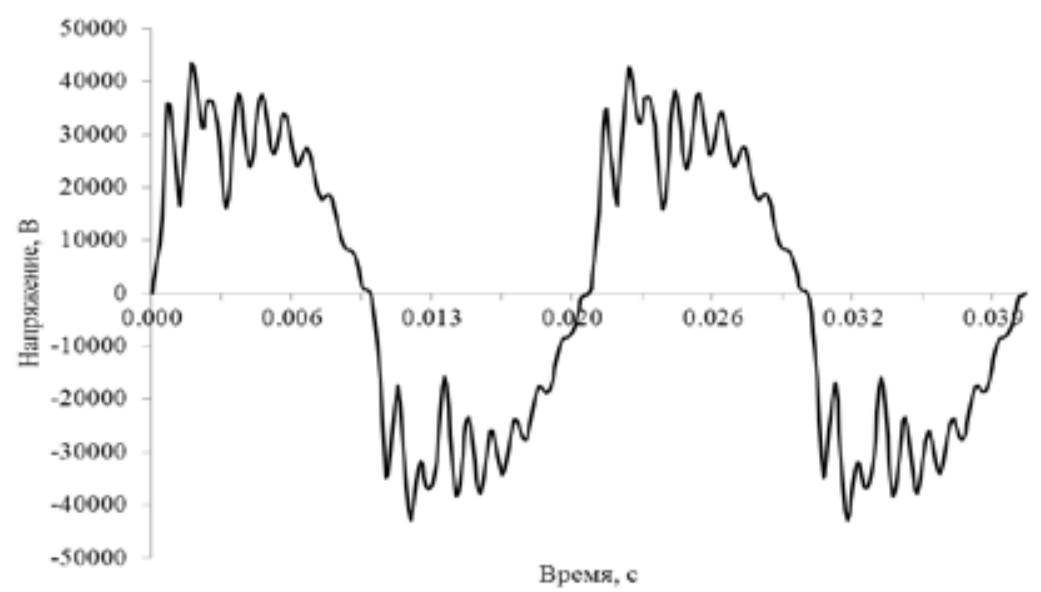

Рис. 5. Кривая напряжения на токоприемнике ЭПС

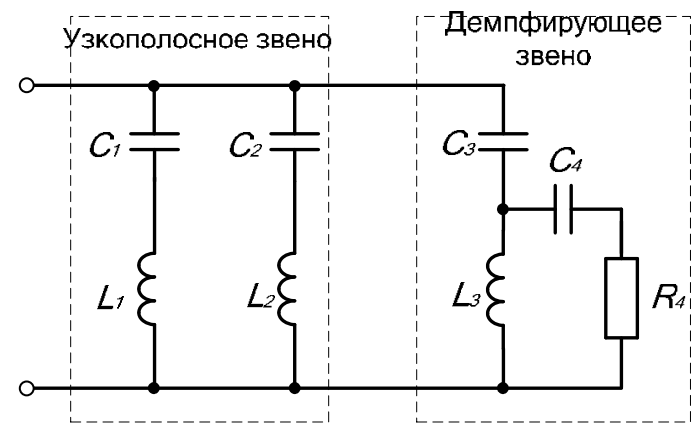

Рис. 6. Схема фильтрокомпенсирующего устройства

Таблица 3. Значения элементов фильтрокомпенсирующего устройства

\begin{tabular}{|c|c|c|c|c|c|c|c|}
\hline C1, мкФ & С2, мкФ & C3, мкФ & C4, мкФ & L1, мГн & L2, мГн & L3, мГн & $\mathrm{R} 4, \mathrm{OM}$ \\
\hline 5,3 & 5,4 & 2,47 & 7,41 & 227 & 79 & 62,5 & 150 \\
\hline
\end{tabular}

На рис. 8 представлена кривая напряжения на токоприемнике электроподвижного состава (ЭПС) (кривая 1). После установки ФКУ суммарный коэффициент гармоник напряжения снизился с 32 до $6 \%$.

Для сравнения приведем характеристики системы тягового электроснабжения с ФКУ, выпускаемым ООО «НИИЭФА-ЭНЕРГО». Схема фильтра изображена на рис. 9. Звенья L1-C1 и L2-C2 образуют двухчастотный фильтр, настроенный на частоты 150 и 350 Гц. Назначение третьего звена - ограничение усиления высших гармоник $(n \geq 10)$.

Частотная характеристика и напряжение на токоприемнике ЭПС при установке ФКУ «НИИЭФА ЭНЕРГО» показаны на рис. 7, 8 (кривая 2). Суммарный коэффициент гармоник

$$
-67-
$$




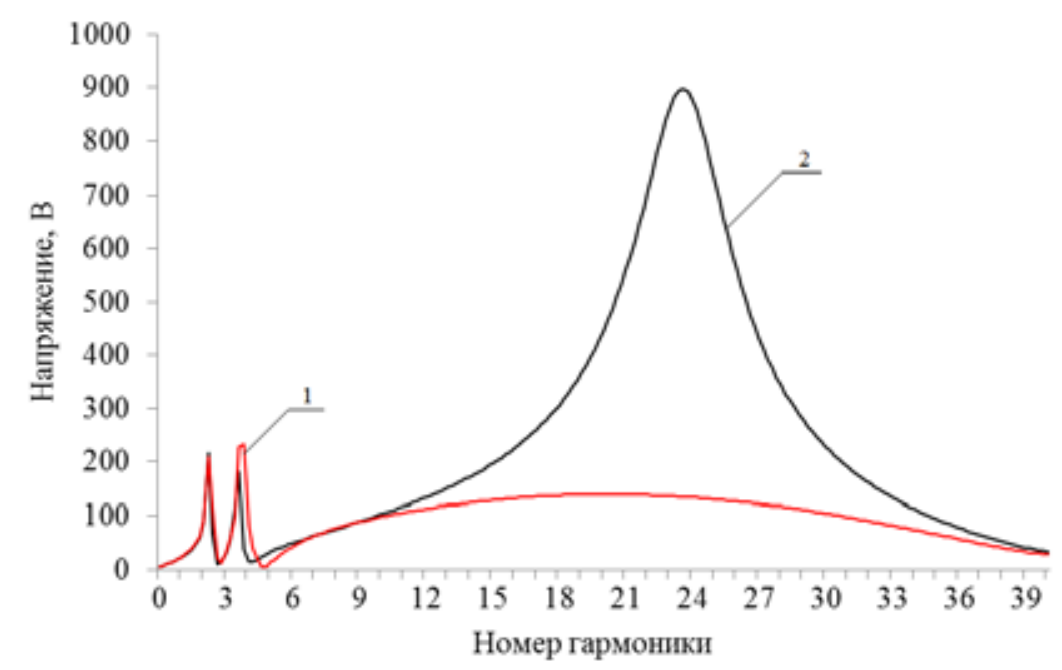

Рис. 7. Частотная характеристика системы тягового электроснабжения

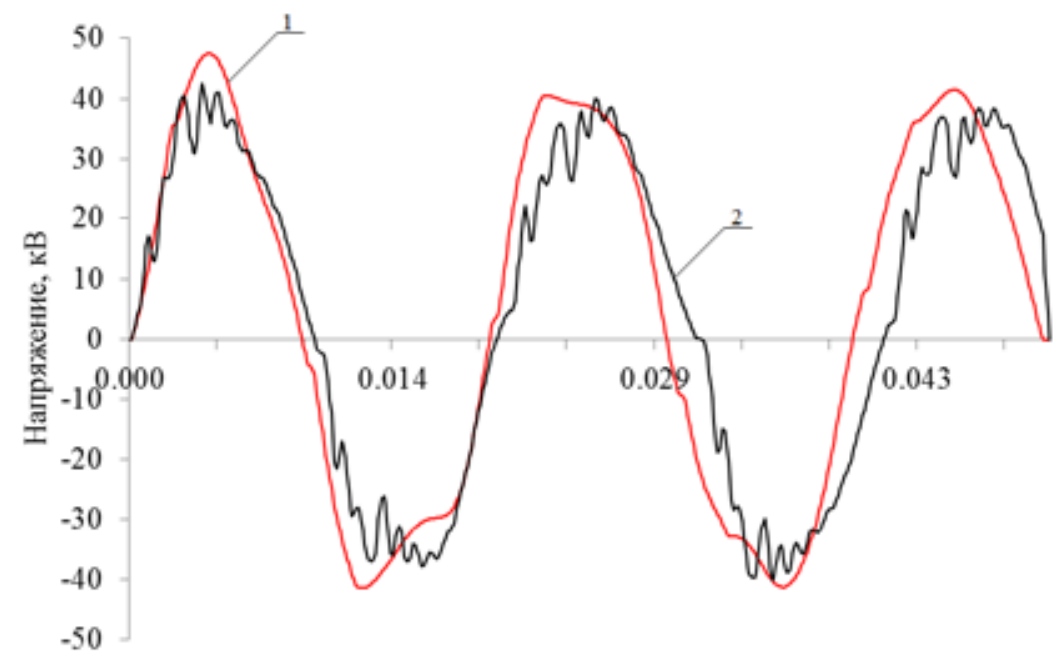

Время, с

Рис. 8. Кривая напряжения на токоприемнике ЭПС

напряжения на токоприемнике составляет 9 \%. В табл. 4 представлены амплитуды гармоник напряжения (в процентах от амплитуды основной гармоники) для всех рассмотренных вариантов.

Сравнение характеристик компенсирующих устройств показывает, что ФКУ, образованное параллельным соединением узкополосных звеньев и демпфирующего фильтра (рис. 6), обеспечивает эффективное ослабление низкочастотных гармоник в спектре напряжения на токоприемнике ЭПС, а также исключает резонансное усиление высокочастотных гармоник. Еще одно преимущество предлагаемого устройства - значительно меньшая суммарная емкость конденсаторов, чем у ФКУ «НИИЭФА ЭНЕРГО». 


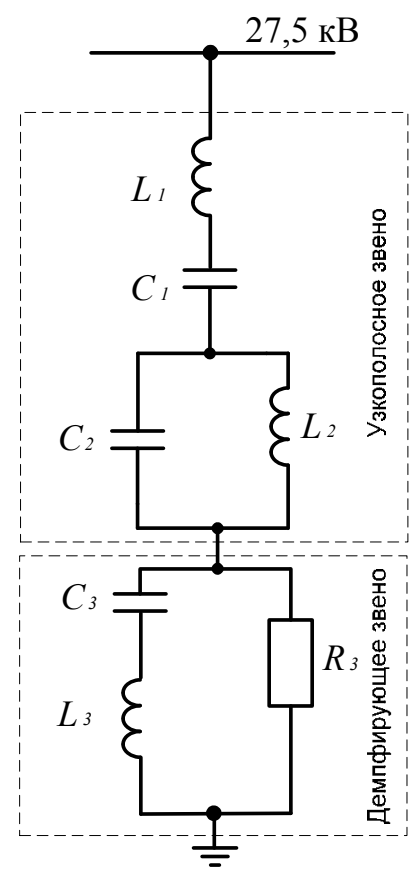

Рис. 9. Схема фильтра производства ООО «НИИЭФА ЭНЕРГО»

Таблица 4. Амплитуды гармоник напряжения для всех рассмотренных вариантов

\begin{tabular}{|l|c|c|c|c|c|c|c|c|c|}
\hline & 1 & 3 & 5 & 7 & 9 & 11 & 13 & 15 & 17 \\
\hline Без ФКУ, \% & 100 & 19,8 & 12,5 & 3,6 & 3,3 & 8,1 & 8,9 & 4,7 & 10,6 \\
\hline ФКУ «НИИЭФА ЭНЕРГО», \% & 100 & 5,7 & 3,4 & 1,5 & 1,3 & 3,1 & 2,6 & 1,0 & 1,3 \\
\hline Предлагаемый вариант ФКУ, \% & 100 & 4,3 & 0,5 & 1,5 & 1,3 & 2,3 & 2,0 & 0,8 & 0,5 \\
\hline
\end{tabular}

\section{Заключение}

В статье предложен общий метод проектирования силовых демпфирующих фильтров, основанный на представлении фильтра в виде резистивно нагруженного реактивного четырехполюсника лестничной структуры. Использование регулярных методов синтеза пассивных цепей позволило создать простую и гибкую процедуру проектирования демпфирующих фильтров, обеспечивающих коррекцию частотных характеристик системы тягового электроснабжения за счет согласования сопротивления фильтра и тяговой сети в заданном диапазоне частот.

Рассмотренный пример продемонстрировал, что предлагаемый вариант ФКУ с демпфирующим фильтром обеспечивает электромагнитную совместимость электроподвижного состава с системой тягового электроснабжения, а также с цепями питания устройств автоматики и телемеханики. Таким образом, показана возможность улучшения техникоэкономических характеристик компенсирующих устройств для систем тягового электроснабжения. 


\section{Список литературы}

[1] Кучумов В. А., Ермоленко Д. В. Показатели качества электроэнергии на токоприемнике и взаимодействие ЭПС с системой тягового электроснабжения переменного тока. Вестник ВНИИЖТ, 1997, 2, 11-16 [Kuchumov V.A., Ermolenko D.V. Indicators of power quality on the current collector, and interaction with the EPS system traction power supply AC, Vestnik of the Railway Research Institute, 1997, 2, 11-16 (in Russian)]

[2] Morrison R. E., Barlow M. J. Continuous overvoltage on A.C. traction systems. IEEE transactions on power apparatus and systems, PAS-102(5), 1983, 1211-1217.

[3] Довгун В. П., Сташков И. А. Анализ качества электроэнергии в сетях тягового электроснабжения переменного тока. Научные проблемы транспорта Сибири и Дальнего Восто$\kappa a, 2014,4,178-181$ [Dovgun V.P., Stashkov I.A.Analysis of electric energy quality in networks of traction power supply AC, Nauchnye problemy transporta Sibiri I Dal'nego Vostoka, 2014, 4, 178-181 (in Russian)]

[4] Герман Л. А., Серебряков А. С., Ермоленко Д. В., Гончаренко В. П. и др. Установки поперечной емкостной компенсации с фильтрацией и демпфированием высших гармоник в тяговых сетях переменного тока. Вестник ВНИИЖТ, 2014, 1, 47-53 [German L.A., Serebriakov A.S., Ermolenko D.V., Goncharenko V.P. Install transverse capacitive compensation with filtering and damping of higher harmonics in the traction network of alternating current, Vestnik of the Railway Research Institute, 2014, 1, 47-53 (in Russian)]

[5] Tan P.-C., Loh P., Holmes D. A robust hybrid compensation system for $25-\mathrm{kV}$ electrified railway applications, IEEE trans. on power electronics, 2004, 19(4), 1043-1052.

[6] Ермоленко Д. В., Молин Н. И., Павлов И. В. и др. Исследование многофункциональных компенсирующих устройств в эксплуатационных условиях. Вестник ВНИИЖТ, 1991, 7, 44-47 [Ermolenko D.V., Molin N.I., Pavlov I.V. at al. Study multifunction compensating devices in operating conditions, Vestnik of the Railway Research Institute, 1991, 7, 44-47 (in Russian)]

[7] Боярская Н.П., Довгун В.П., Егоров Д.Э. и др. Синтез фильтрокомпенсирующих устройств для систем электроснабжения: коллективная монография. Ред. В.П. Довгун. Красноярск: Сиб. федер. ун-т, 2014, 192 с. [Boiarskaia N.P., Dovgun V.P., Egorov D.E. at al. Synthesis of var compensating devices for power supply systems. Ed. By V.P.Dovgun. Krasnoyarsk, SibFU, 2014, 192 p. (in Russian)]

[8] Матханов П. Н. Основы синтеза линейных электрических иепей. М.: Высшая школа, 1976, 208 с. [Matkhanov P.N. Fundamentals of synthesis of linear electrical circuits, Moscow, Vysshaia shkola, 1976, 208 p. (in Russian)]

[9] Лэм Г. Аналоговые и изифровые фильтры. М.: Мир, 1982, 592 с. [Lem G. Analog and digital filters, Moscow, Mir, 1982, 592 p. (in Russian)]

[10] Ханзел Г. Справочник по расчету фильтров. Пер. с англ. под ред. А. Е. Знаменского, М.: Сов. радио, 1974, 287 с. [Khazel G Guide to designing filters. Transl. from English. Ed. By A.Е. Znamenskii, Moscow, Sov. radio, 1974, 287 p. (in Russian)] 